\title{
Erratum
}

\section{A SQUID System for Low-Drift Magnetization Measurements}

\section{H. Rogalla and C. Heiden*}

Institut für Angewandte Physik, Universität Münster, D-4400 Münster, Fed. Rep. Germany

Applied Physics 14, 161-168 (1977)

Erraneously, a wrong printing block was used for Fig. 1. It should be replaced by the following figure.

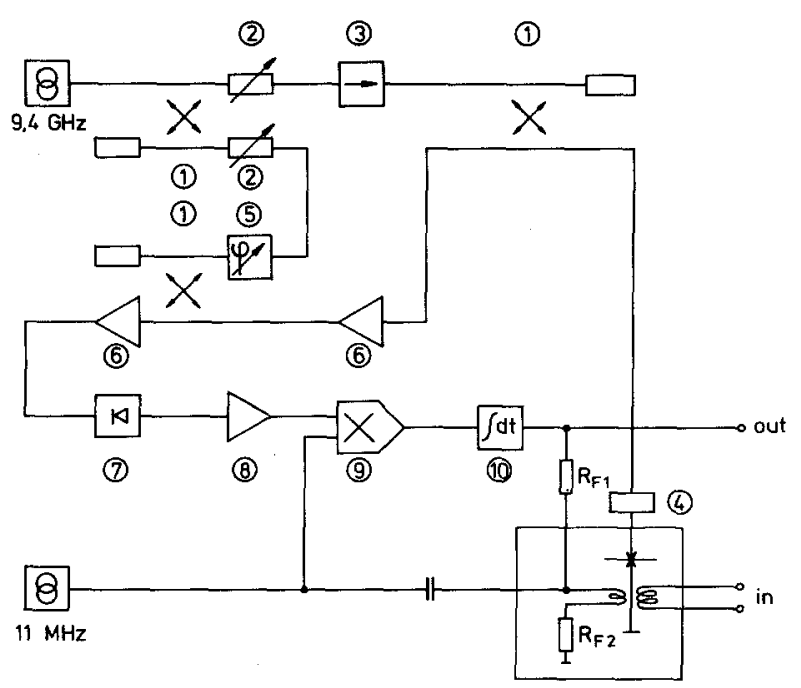

Fig. 1. Block diagram of microwave biased of SQUID electronics. 1) directional coupler, 2) attenuatur, 3) isolator, 4) impedance transformer, 5) phase shifter, 6) tunnel diode amplifier, 7) Schottky diode, 8) video amplifier, 9) phase detector, 10) integrator 